\title{
Karyotyping of Fluconazole-Resistant Yeasts with Phenotype Reported as Candida krusei or Candida inconspicua
}

\author{
S. MATA ESSAYAG, ${ }^{1}$ G. G. BAILY, ${ }^{2}$ D. W. DENNING,${ }^{3}$ AND J. P. BURNIE ${ }^{1 *}$ \\ Department of Medical Microbiology, Manchester Royal Infirmary, University of Manchester, Manchester M13 $9 W L,{ }^{1}$ \\ Department of Infectious Diseases and Tropical Medicine (Monsall Unit), North Manchester District General \\ Hospital, Manchester M8 6RB, ${ }^{2}$ and Department of Medicine, Hope Hospital, University of \\ Manchester, Salford M6 $8 \mathrm{HD},{ }^{3}$ United Kingdom
}

\begin{abstract}
The yeasts Candida krusei and Candida inconspicua have similar phenotypes, which may make discrimination of these organisms difficult. In this study we determined the karyotypes of 51 isolates of these two yeast species by contour-clamped homogeneous electric field electrophoresis. We found that the 43 isolates that had the $C$. krusei phenotype had three karyotype-specific characteristics. These isolates produced either two or three bands between 2,000 and $3,000 \mathrm{~kb}$ and no band between 1,300 and $2,000 \mathrm{~kb}$, and there was either a single bright band at 1,300 or $1,200 \mathrm{~kb}$ or two separate bands at $1,300,1,200$, or $1,100 \mathrm{~kb}$. Using this technique, we were able to distinguish 27 different $C$. krusei types on the basis of band variations. The seven isolates identified as $C$. inconspicua on the basis of phenotype differed in that they produced at least one band between 1,300 and 2,000 kb. These isolates produced six to nine bands, in contrast to $C$. krusei strains, which produced three to six bands. The MIC of fluconazole for all of the isolates was at least $12.5 \mathrm{mg} / \mathrm{liter}$, as determined by a broth dilution method.
\end{abstract}

Candida krusei has recently emerged as an important opportunistic pathogen that causes infections, particularly in immunocompromised, critically ill, and human immunodeficiency virus (HIV)-positive patients $(1,4,8,13,15,21)$. When this organism is cultured from blood, the rate of mortality has been reported to be between 45 and $100 \%(6,30)$. The increase in the rate of isolation of $C$. krusei may be due to the use of fluconazole both for prophylaxis and for treatment $(1,4,13,25$, 32). C. krusei is resistant to fluconazole both in the laboratory and when the drug is used therapeutically $(2,14)$.

Isolates are identified as $C$. krusei strains on the basis of a set of phenotypic characteristics. These characteristics are sufficiently nondiscriminatory that in a clinical laboratory a member of a similar species, such as Candida inconspicua, could be misidentified as a $C$. knisei strain. The phenotypic characteristics used to identify $C$. krusei include colony morphology; the presence of pseudohyphae, true hyphae, and elongate blastoconidia; the absence of chlamydoconidia and germ tubes; surface growth that has the ability to form a climbing film on the sides of glass containers; glucose fermentation; assimilation of glucose, glycerol, DL-lactic acid, succinate, ethanol, and $\mathrm{N}$ acetylglucosamine; lack of assimilation of galactose, L-sorbose, sucrose, D-ribose, L-rhamnose, maltose, cellobiose, trehalose, melibiose, raffinose, melezitose, inulin, starch, D-xylose, L-arabinose, D-arabinose, erythritol, ribitol, D-mannitol, salicin, inositol, lactose, galactitol, and glucosamine; failure to grow when potassium nitrate is the nitrogen source; and growth in a vitamin-free medium (28).

C. inconspicua is distinguished from $C$. krusei by its failure to produce hyphae on corn meal agar, the presence of a primitive pseudomycelium, its inability to ferment glucose and assimilate $N$-acetylglucosamine, its ability to assimilate glucosamine, and its failure to grow in a vitamin-free medium. Six strains of $C$. inconspicua have been described, and the type strain is one of the four isolates obtained from sputum samples (22).

${ }^{*}$ Corresponding author. Mailing address: Department of Medical Microbiology, Clinical Sciences Building, Manchester Royal Infirmary, Oxford Road, Manchester M13 9WL, United Kingdom.
Recent advances in molecular biology include the application of pulsed-field gel electrophoresis (PFGE) to the taxonomy of yeasts $(3,7,10,11,16-20,24,26,30)$. Contour-clamped homogeneous electric field (CHEF) electrophoresis is a variant of this technique which improves chromosomal resolution (9). The aim of this study was to characterize a group of clinical isolates which were initially identified in the laboratory by routine ID 32C strip tests (Bio-Mérieux, Marcy-l'Étoile, France) as either $C$. krusei or $C$. inconspicua strains. Phenotypes were determined by conventional methods and were compared with genotypes determined by CHEF electrophoresis. Suitable type strains were obtained from reference collections. Our data provide the basis for a clear separation of the species $C$. krusei and $C$. inconspicua. This is important as there is a need to establish whether infecting isolates have an endogenous origin or are epidemiologically related. Our data also show that no specific karyotype pattern is produced by $C$. inconspicua isolates.

\section{MATERIALS AND METHODS}

Isolates. Ten control isolates were obtained from culture collections. $C$. kruse ATCC $6258^{\mathrm{T}}\left(\mathrm{T}=\right.$ type strain), ATCC $20298^{\mathrm{T}}$, and ATCC $62404^{\mathrm{T}}, C$. incon spicua ATCC $16783^{\mathrm{T}}$ and ATCC $34637^{\mathrm{T}}$, and Candida rugosa ATCC $20306^{\mathrm{T}}$ were obtained from the American Type Culture Collection; C. krusei $9112022^{\mathrm{T}}$ and $C$. inconspicua $9312113^{\mathrm{T}}$ and $8908012^{\mathrm{T}}$ were obtained from Bio-Mérieux: and C. krusei $198^{\mathrm{T}}$ was obtained from the Manchester University Culture Collection. Nine isolates were obtained from blood (one isolate), sputa (four isolates), or throat swabs (four isolates) from HIV-negative patients; 20 isolates were obtained from HIV-positive patients who had received fluconazole therapy at either Monsall Hospital, Hope Hospital, or Manchester Royal Infirmary Hospital; and 13 isolates were obtained from the Public Health Laboratory, Bristol, England.

Yeast identification and phenotypic tests. All yeast strains were either obtained from a culture collection or identified by an ID 32C strip test read with an ATB reader (Bio-Mérieux) as $C$. krusei or $C$. inconspicua. Later, the strains were identified again and were examined to determine whether they produced chlamydoconidia (12) and mycelia on Dalmau culture plates (23). A glucose fermentation test was performed in basal medium I supplemented with glucose and incubated at $30^{\circ} \mathrm{C}$ for $48 \mathrm{~h}(23)$. Surface growth and the ability to form a climbing film were assessed in Sabouraud broth (Unipath, Ltd., Basingstoke, England) by incubating preparations at $30^{\circ} \mathrm{C}$ for $48 \mathrm{~h} \mathrm{(23)}$. Growth in a vitamin-free medium was tested in a chemically defined medium containing $2 \%$ agar by incubating preparations at $30^{\circ} \mathrm{C}$ for 7 days $(5)$. 
TABLE 1. Phenotypes of the C. krusei and $C$. inconspicua isolates

\begin{tabular}{lcccc}
\hline Group & $\begin{array}{c}\text { No. of } \\
\text { isolates }\end{array}$ & $\begin{array}{c}\text { True hyphae or } \\
\text { pseudohyphae } \\
\text { produced }\end{array}$ & $\begin{array}{c}\text { N-Acetyl- } \\
\text { glucosamine } \\
\text { assimilation }\end{array}$ & $\begin{array}{c}\text { ID 32C } \\
\text { profile }\end{array}$ \\
\hline 1a & 30 & + & + & 0300010001 \\
$1 \mathrm{~b}$ & 5 & + & - & 0200000001 \\
$1 \mathrm{c}$ & 3 & + & - & 0200010401 \\
1d & 3 & - & - & 0200010001 \\
1e & 2 & - & - & 0300010001 \\
2 & 7 & - & - & 0200010005 \\
\hline
\end{tabular}

Yeast morphology and colony morphology were determined with malt extract agar cultures by growing isolates at $30^{\circ} \mathrm{C}$ for 2 days. Yeast cells were stored in sterile distilled water at room temperature and on Sabouraud medium (Unipath, Ltd.) slants at $4^{\circ} \mathrm{C}$.

Antifungal agent susceptibility testing. Susceptibility to fluconazole was determined by the broth tube dilution method (4).

Preparation of yeast chromosomal DNA. The yeast chromosomal DNA used for PFGE was prepared by a modification of the method of Schwartz and Cantor (27) described previously (17)

PFGE. Electrophoresis was performed with a model CHEF-DR11 system (Bio-Rad, Richmond, Calif.). Plugs were loaded into $1.5 \%$ (wt/vol) agarose (Bio-Rad) gels in $0.5 \%$ TBE buffer.

The DNA was resolved by CHEF electrophoresis by using conditions described by Doi et al. (11). In protocol 1, a 300-s switch interval at $130 \mathrm{~V}$ for 24 $\mathrm{h}$ was followed by a 1,000 -s switch interval at $90 \mathrm{~V}$ for $48 \mathrm{~h}$. In protocol 2, to examine the larger chromosomes, a 200 -s switch interval at $150 \mathrm{~V}$ for $24 \mathrm{~h}$ was followed by a $700-\mathrm{s}$ switch interval at $100 \mathrm{~V}$ for $48 \mathrm{~h}$.

The gels were stained with ethidium bromide $(0.5 \mu \mathrm{g} / \mathrm{ml}$ in distilled water) for $15 \mathrm{~min}$ and destained in distilled water for $3 \mathrm{~h}$. The DNA bands were visualized with short-wavelength UV light $(254 \mathrm{~nm})$ and photographed. The band patterns in adjacent lanes were compared visually.

Reference strain. Candida albicans SGY 126 was used as the reference strain to determine the molecular sizes of the chromosome bands in PFGE gels (17, $18)$.

\section{RESULTS}

Our analysis of the phenotypic characteristics of the strains studied revealed that there were two major groups. All of the group 1 isolates produced flat, dry, white to cream colonies and elongated blastoconidia. They fermented glucose, grew on a vitamin-free medium and on the surface of Sabouraud broth, and did not assimilate glucosamine. In contrast, the group 2 isolates produced soft, smooth, greyish cream colonies and small, oval blastoconidia. They did not ferment glucose, grow on a vitamin-free medium, or grow on the surface of Sabouraud broth, and they assimilated glucosamine.

The group 1 isolates were identified as $C$. krusei strains (28). The members of this group could be further subdivided on the basis of their abilities to produce true hyphae or pseudohyphae and differences in their ID $32 \mathrm{C}$ profiles (Table 1). The latter reflected variations in $\mathrm{N}$-acetylglucosamine and levulinate as-

TABLE 2. Bands found in C. krusei CHEF electrophoresis types

\begin{tabular}{|c|c|c|c|c|c|c|c|c|c|c|c|c|c|}
\hline \multirow{2}{*}{$\begin{array}{c}\text { DNA } \\
\text { type }\end{array}$} & \multicolumn{11}{|c|}{ Band at ${ }^{a}$ : } & \multirow{2}{*}{$\begin{array}{l}\text { Total no. } \\
\text { of bands }\end{array}$} & \multirow{2}{*}{$\begin{array}{l}\text { No. of } \\
\text { isolates }\end{array}$} \\
\hline & $\begin{array}{c}3,000 \\
\mathrm{~kb}\end{array}$ & $\begin{array}{c}2,900 \\
\mathrm{~kb}\end{array}$ & $\begin{array}{c}2,800 \\
\mathrm{~kb}\end{array}$ & $\begin{array}{c}2,600 \\
\mathrm{~kb}\end{array}$ & $\begin{array}{c}2,000 \\
\mathrm{~kb}\end{array}$ & $\begin{array}{c}1,300 \\
\mathrm{~kb}\end{array}$ & $\begin{array}{c}1,200 \\
\mathrm{~kb}\end{array}$ & $\begin{array}{c}1,100 \\
\mathrm{~kb}\end{array}$ & $\begin{array}{c}1,000 \\
\mathrm{~kb}\end{array}$ & $\begin{array}{l}800 \\
\mathrm{~kb}\end{array}$ & $\begin{array}{c}600 \\
\mathrm{~kb}\end{array}$ & & \\
\hline 2 & + & - & - & + & - & + & - & + & - & - & - & 4 & 1 \\
\hline 3 & + & - & - & + & - & + & + & - & - & - & - & 4 & 1 \\
\hline 4 & + & + & - & - & - & - & + & + & - & - & - & 4 & 3 \\
\hline 5 & + & - & - & + & - & - & + & + & - & - & - & 4 & 1 \\
\hline 7 & + & + & - & - & + & - & $\mathrm{U}$ & - & - & + & - & 5 & 1 \\
\hline 8 & - & + & - & + & - & + & + & - & - & - & - & 4 & 1 \\
\hline $9^{c}$ & - & + & - & + & - & - & $\mathbf{U}$ & - & - & - & - & 3 & 4 \\
\hline $10^{d}$ & + & - & + & + & - & - & $\mathbf{U}$ & - & - & - & - & 4 & 2 \\
\hline 11 & - & + & + & + & - & $\mathrm{U}$ & - & - & - & - & - & 4 & 3 \\
\hline 12 & - & + & + & - & + & - & $\mathrm{U}$ & - & - & - & + & 5 & 2 \\
\hline 13 & + & - & + & + & - & $\mathrm{U}$ & - & - & - & - & - & 4 & 1 \\
\hline 14 & - & + & + & - & - & - & + & + & - & - & - & 4 & 6 \\
\hline 16 & + & - & + & - & - & - & + & + & - & - & - & 4 & 1 \\
\hline 17 & + & - & - & + & - & - & - & + & + & - & - & 4 & 1 \\
\hline $18^{e}$ & + & - & + & - & - & + & + & - & - & - & - & 4 & 1 \\
\hline 19 & - & + & + & + & - & + & + & - & - & - & - & 5 & 1 \\
\hline 20 & + & - & + & + & - & $\mathrm{U}$ & - & - & - & - & - & 4 & 1 \\
\hline 21 & - & + & + & + & - & - & + & - & + & - & - & 5 & 1 \\
\hline 22 & - & + & + & + & - & - & + & + & - & - & - & 5 & 1 \\
\hline 23 & + & - & + & + & - & - & + & + & - & - & - & 5 & 1 \\
\hline 24 & - & + & + & + & - & + & + & + & - & - & - & 6 & 1 \\
\hline 25 & - & + & + & $+^{f}$ & - & - & + & + & - & - & - & 5 & 1 \\
\hline $26^{g}$ & + & - & $+^{h}$ & + & - & - & $\mathrm{U}$ & - & - & - & - & 4 & 1 \\
\hline $27^{i}$ & + & - & $+^{h}$ & + & - & $\mathrm{U}$ & - & - & - & - & - & 4 & 1 \\
\hline
\end{tabular}

${ }^{a}$ Band sizes are approximate.

${ }^{b} \mathrm{U}$, band cannot be resolved.

${ }^{c}$ Includes strain $9112022^{\mathrm{T}}$

${ }^{d}$ Includes strain ATCC $62404^{\mathrm{T}}$.

${ }^{e}$ Strain $198^{\mathrm{T}}$.

$f$ Band occurs at $2,500 \mathrm{~kb}$.

${ }^{g}$ Strain ATCC $6258^{\mathrm{T}}$

${ }^{h}$ Band occurs at $2,700 \mathrm{~kb}$

${ }^{i}$ Strain ATCC $20298^{\mathrm{T}}$ 

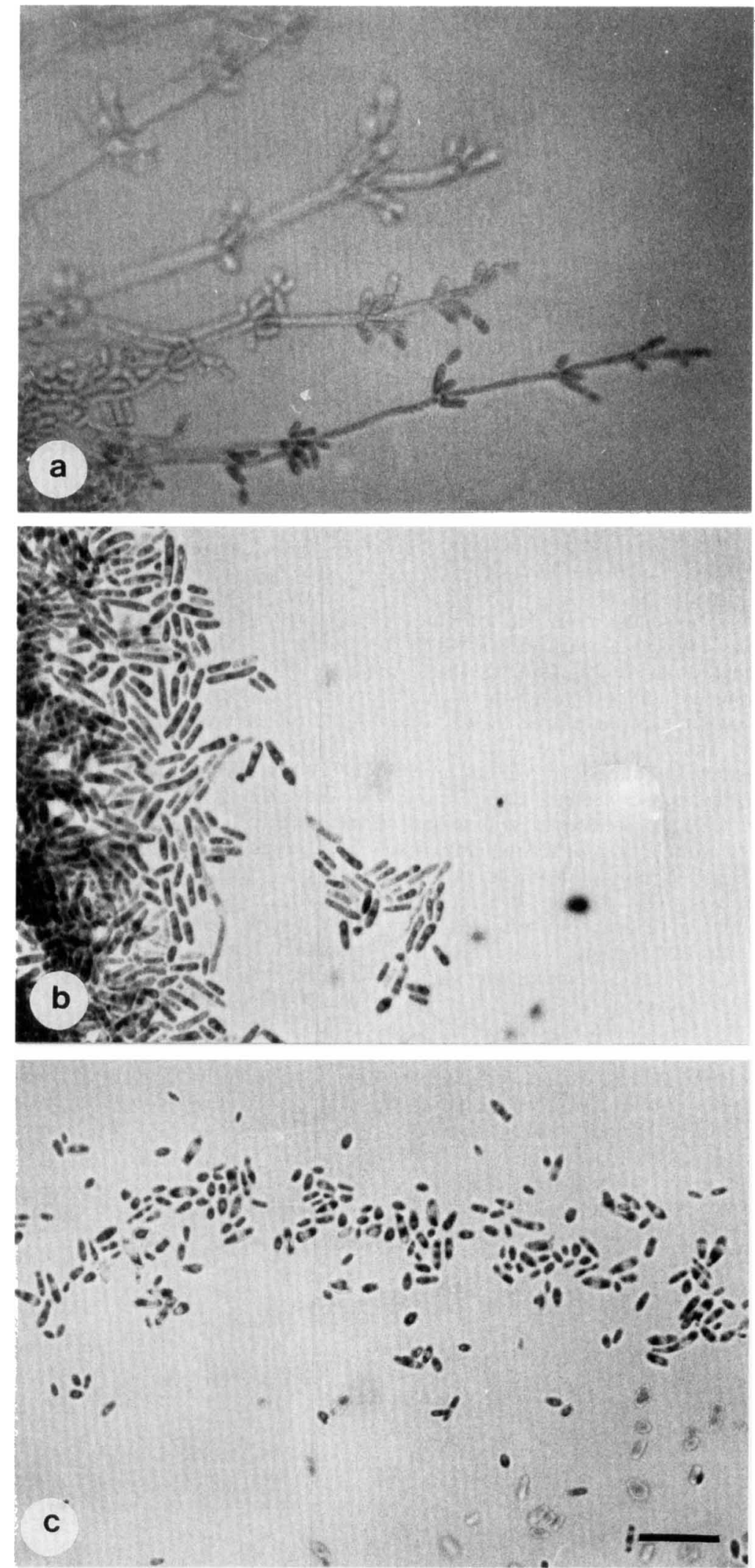

FIG. 1. Dalmau plate cultures on corn meal agar after incubation for 3 days at $25^{\circ} \mathrm{C}$. (a) $C$. krusei group 1a, $1 \mathrm{~b}$, and $1 \mathrm{c}$ long mycelia with verticillate branches. (b) C. krusei group $1 \mathrm{~d}$ and $1 \mathrm{e}$ isolates produce no mycelium. (c) C. inconspicua cells are oval and occur singly or in pairs. Bar $=20 \mu \mathrm{m}$. 


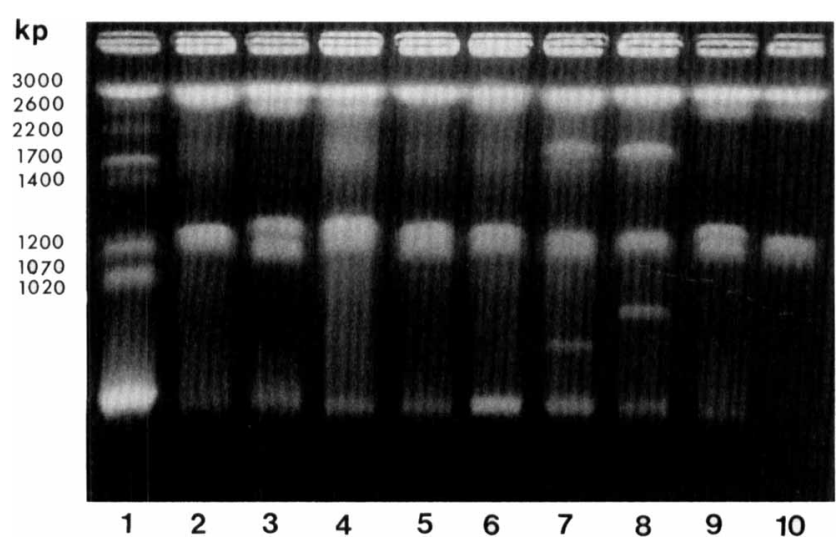

FIG. 2. CHEF electrophoresis, protocol 1. Lane 1, C. albicans SGY 126 molecular weight marker; lanes 2 through $10, C$. krusei DNA types 1 to 9 , respectively.

similation, while the former was reconfirmed as an individual test. Group 1a included control isolates C. krusei ATCC $6258^{\mathrm{T}}$, ATCC $62404^{\mathrm{T}}, 198^{\mathrm{T}}$, and $9112022^{\mathrm{T}}$. Group 1c included $C$. krusei ATCC 20298 ${ }^{\mathrm{T}}$.

All of the group $1 \mathrm{a}, 1 \mathrm{~b}$, and $1 \mathrm{c}$ isolates produced long mycelia with verticillate branches (Fig. 1a), a characteristic which was not observed in the group 1d and 1e isolates (Fig. 1b).

All of the group 2 isolates were small oval yeasts that had a 0200010005 ID 32C profile, did not produce true hyphae or pseudohyphae (Fig. 1c), and did not assimilate $N$-acetylglucosamine. On the basis of these characteristics the group 2 isolates were identified as $C$. inconspicua strains (22). Group 2 included three of the four culture collection isolates and four clinical isolates obtained from HIV-positive patients. $C$. inconspicua ATCC $34637^{\mathrm{T}}$ had a unique ID $32 \mathrm{C}$ profile (1000310013), produced white wrinkled colonies, did not ferment glucose, did not produce a pellicle, did not grow on vitamin-free medium, and did not assimilate $N$-acetylglucosamine or glucosamine. Thus, the phenotype of this strain was similar to the phenotype of $C$. rugosa (29).

The MIC of fluconazole for the isolates which we studied ranged from 12.5 to $100 \mathrm{mg} /$ liter.

The electrophoretic karyotypes of the isolates were highly reproducible. This was confirmed by performing each analysis at least three times. The sizes of the major bands varied between 1,100 and $3,000 \mathrm{~kb}$. The isolates classified on the basis of phenotype as $C$. krusei strains all had three specific characteristics. Each isolate produced two or three bands between 2,000 and $3,000 \mathrm{~kb}$ and at least one band at either 2,900 or $3,000 \mathrm{~kb}$ (Table 2). Each isolate produced either a single bright band at 1,300 or $1,200 \mathrm{~kb}$ that could not be resolved or two separate bands at $1,300,1,200$, or $1,100 \mathrm{~kb}$. No isolate produced a band between 1,300 and $2,000 \mathrm{~kb}$.

In contrast, each group 2 isolate produced at least one band between 1,300 and $2,000 \mathrm{~kb}$, and this characteristic distinguished the group 1 isolates from the group 2 isolates. The group 1 isolates produced between three and six bands, while the group 2 isolates produced between six and nine bands (Table 2).

On the basis of variations in the patterns of the bands we divided the 43.C. krusei isolates into 27 types, and the most common type was represented by only six isolates. In this analysis the distinctions were based on single or multiple differences in bands (Table 2). Figure 2 shows examples of isolates examined by protocol 1 ; lanes 2 through 10 contained

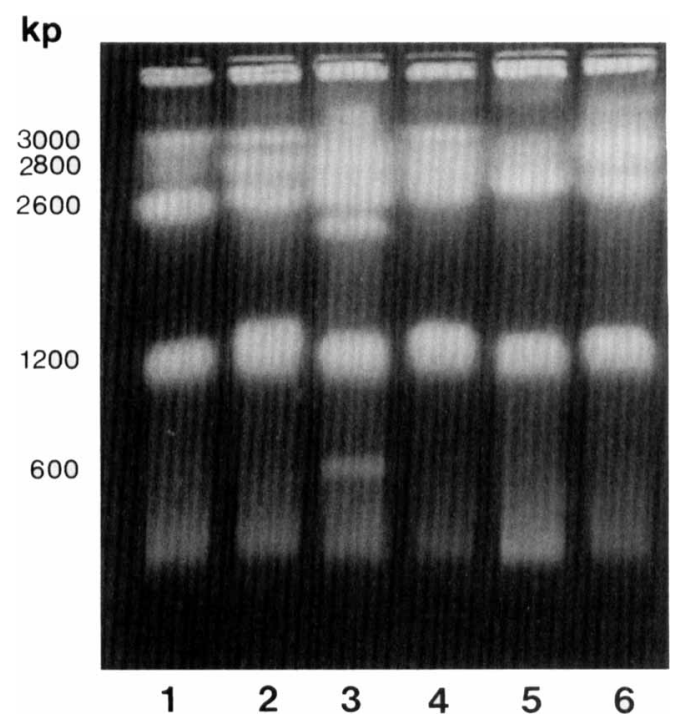

FIG. 3. CHEF electrophoresis, protocol 2. Lanes 1 through 4, C. knusei DNA types 10 through 13 , respectively; lanes 5 and $6, C$. krusei DNA type 1 .

DNA types 1 to 9 , respectively. When isolates were assessed by protocol 2, the higher-molecular-weight chromosomes split more effectively. This is shown in Fig. 3; lanes 1 through 4 contained DNA types 10 through 13 , respectively. Figure 3, lanes 5 and 6, contained DNA type 1 strains, whose bands at 2,900 and $2,800 \mathrm{~kb}$ can be clearly differentiated. An example of DNA type 14 is shown in Fig. 4, lane 10.

When the three control isolates of $C$. inconspicua were compared (Fig. 4, lanes 6 through 8, and Table 3), we found that each produced a unique pattern. Thus, it was impossible to define a karyotype for $C$. inconspicua as represented by a single type strain. In contrast, all four clinical isolates obtained from HIV-positive patients (Fig. 4, lanes 2 through 5, and Table 3) produced conserved bands at $3,000,2,400,1,400$, and $1,100 \mathrm{~kb}$. The isolates in lanes 2 and 4 were obtained from the same patient (DNA type 1) on days 6 months apart, and the patterns produced by these isolates showed that there was a band at $2,800 \mathrm{~kb}$ which was variable. The remaining isolates (Fig. 4 , lanes 3 and 5) were obtained from two HIV-positive patients with no obvious epidemiological link (DNA types 2 and 3,

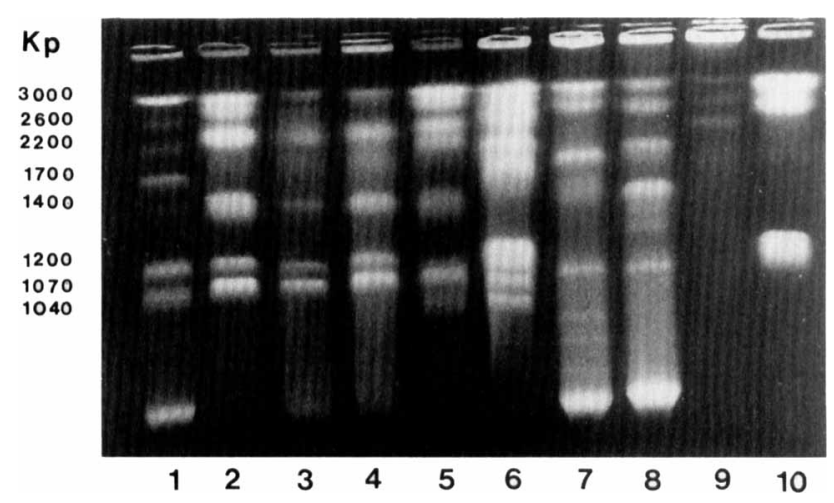

FIG. 4. CHEF electrophoresis, protocol 2, Lane 1, C albicans SGY 126 molecular weight marker; lanes 2 through 5 , clinical isolates of $C$. inconspicua lane $6, C$. inconspicua $9372113^{\mathrm{T}}$; lane $7, C$. inconspicua $890812^{\mathrm{T}}$; lane $8, C$. inconspicua ATCC $16783^{\mathrm{T}}$; lane $9, C$. inconspicua ATCC $34637^{\mathrm{T}}$; lane $10, C$. krusei DNA type 14. 
TABLE 3. Bands found in C. inconspicua CHEF electrophoresis types

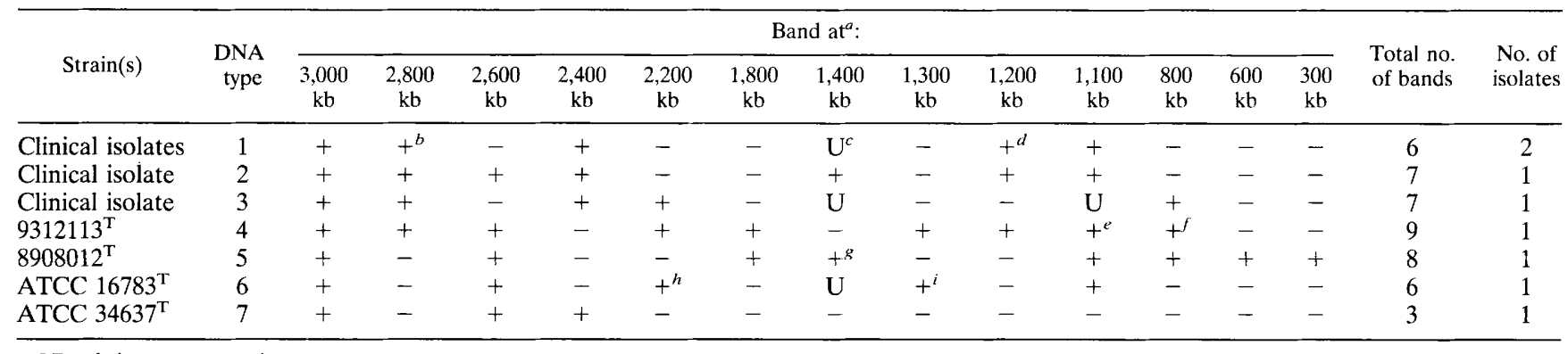

${ }^{a}$ Band sizes are approximate.

${ }^{b}$ Position variable.

c $\mathrm{U}$, band cannot be resolved.

${ }^{d}$ Band occurs at $1,250 \mathrm{~kb}$.

${ }^{e}$ Band occurs at $1,070 \mathrm{~kb}$.

${ }^{f}$ Band occurs at $900 \mathrm{~kb}$.

${ }^{g}$ Band occurs at $1,500 \mathrm{~kb}$.

${ }^{h}$ Band occurs at $2,100 \mathrm{~kb}$.

${ }^{i}$ Band occurs at $1,350 \mathrm{~kb}$.

respectively). C. inconspicua ATCC $34637^{\mathrm{T}}$ produced a unique pattern (Fig. 4, lane 9) with only three bands. A similar pattern was obtained with $C$. rugosa ATCC $20306^{\mathrm{T}}$, confirming that this strain was neither a $C$. krusei strain nor a $C$. inconspicua strain (Table 3, DNA type 7).

\section{DISCUSSION}

In this study we examined $30 \mathrm{C}$. krusei isolates that had the classical phenotype (Table 1, group 1a) and 13 C. krusei isolates whose phenotypes were different (groups $1 \mathrm{~b}$ through $1 \mathrm{e}$ ). All of these isolates shared three karyotype characteristics. Each produced either two or three high-molecular-weight bands. Previously, Doi et al. (11) examined three strains of $C$. krusei and found that the chromosomes all hybridized to a ribosomal DNA-specific probe. All of the isolates also produced either a single band at 1,300 or $1,200 \mathrm{~kb}$ that could not be resolved or two separate bands at $1,300,1,200$, or $1,100 \mathrm{~kb}$; the brightness and width of the single bands suggested that there were at least two chromosomes. No isolate produced a band between 1,300 and $2,000 \mathrm{~kb}$.

Iwaguchi et al. (16) examined three strains of C. krusei and found that these organisms produced two bands between 2,000 and $3,000 \mathrm{~kb}$ and a single bright band between 1,200 and 1,600 $\mathrm{kb}$ that could not be resolved.

Wickes et al. (31) concluded that the karyotype of $C$. krusei was nearly identical to the karyotype of Issatchenkia orientalis and that the number of chromosomes was five. This conclusion was based on the presence of four bands, one of which, the largest band, was very intense. After quantifying bands with a laser fluorescent gel scanner, Doi et al. (11) concluded that the number of bands was five and that the bands represented seven, eight, or nine chromosomes. In contrast, we found that the number of bands varied from three to six. This made it difficult to estimate both the number of chromosomes and the total size of the genome. Some isolates (Table 2, DNA types 6, 7 , and 12) had small chromosomes (either 600 or $800 \mathrm{~kb}$ ). A similar phenomenon has been reported for $C$. albicans (24).

The differences in band patterns demonstrated that CHEF electrophoresis can be used to determine C. krusei types. All of our isolates typed, and discrimination was excellent; the 43 isolates fell into 27 groups. The reproducibility in this study was good. Some of the variation was due to duplication or movement of the ribosomal chromosome, and, in the case of $C$. albicans, this is known to be an unstable characteristic $(3,11$, $16,18-20,24,26)$. A restriction enzyme analysis performed with Hinfl followed by Southern hybridization with the CkF 1,2 DNA probe recently revealed 48 distinct types among $58 C$. krusei isolates (6). This is an alternative typing method that is simpler, but, on its own, this method cannot be used to confirm the identity of a yeast being investigated.

When the isolates identified on the basis of phenotype as $C$. inconspicua were examined, it was apparent that each of the control isolates had a unique karyotype. Thus, it was impossible to define a specific isolate as the type strain. We cannot eliminate the possibility that there are several distinct species of yeasts which have the $C$. inconspicua phenotype. In contrast, the four clinical isolates all produced bands at 3,000, 2,400, 1,400 , and $1,100 \mathrm{~kb}$. All of these strains were resistant to fluconazole in the laboratory and came from HIV-positive patients with oral candidosis who had relapsed during fluconazole therapy. This may represent the emergence of a specific yeast species which phenotypically is identical to $C$. inconspicua and has its own unique karyotype. We are currently in the process of partially sequencing parts of the large-subunit ribosomal DNAs of these isolates to prove this. Fluconazoleresistant yeasts have become increasingly important as fluconazole is used widely to treat oral and esophageal candidosis in HIV-positive patients and for prophylaxis in neutropenic patients $(1,4,13,32)$.

\section{ACKNOWLEDGMENTS}

We thank the Consejo de Desarrollo Cientifico y Humanistico de la Universidad Central de Venezuela for sponsoring S. Mata Essayag.

We also thank Bio-Mérieux for confirming API profiles and supplying C. krusei $9112022^{\mathrm{T}}$ and C. inconspicua $9312113^{\mathrm{T}}$ and $8908012^{\mathrm{T}}$.

\section{REFERENCES}

1. Akova, M., H. E. Akalin, O. Uzon, and D. Gür. 1991. Emergence of Candida krusei infections after therapy of oropharyngeal candidiasis with fluconazole. Eur. J. Clin. Microbiol. Infect. Dis. 10:598-599.

2. Anaissie, E. J., N. C. Karyotakis, R. Hachem, M. C. Dignani, J. H. Rex, and V. Paetznick. 1994. Correlation between in vitro and in vivo activity of antifungal agents against Candida species. J. Infect. Dis. 170:384-389.

3. Asakura, K., S.-I. Iwaguchi, M. Homma, T. Sukai, K. Hibashide, and K. Tanaka. 1991. Electrophoretic karyotypes of clinically isolated yeasts of Candida albicans and Candida glabrata. J. Gen. Microbiol. 137:2531-2538.

4. Baily, G. G., F. M. Perry, D. W. Denning, and B. K. Mandal. 1994. Fluconazole-resistant candidosis in an HIV cohort. AIDS 8:787-792.

5. Barnett, J. A., R. W. Payne, and D. Yarrow. 1979. A guide to identifying and 
classifying yeasts, p. 46. Cambridge University Press, Cambridge.

6. Carlotti, A., R. Grillot, A. Couble, and J. Villard. 1994. Typing of Candida krusei clinical isolates by restriction endonuclease analysis and hybridization with CkF1,2 DNA probe. J. Clin. Microbiol. 32:1691-1699.

7. Carruba, G., E. Pontieri, F. De Bernadis, P. Martino, and A. Cassone. 1991. DNA fingerprinting and electrophoretic karyotype of environmental and clinical isolates of Candida parapsilosis. J. Clin. Microbiol. 29:916-922.

8. Case, P. C., A. P. MacGowan, N. M. Brown, and D. S. Preeves. 1991 Prophylactic oral fiuconazole and Candida fungemia. Lancet 337:790.

9. Chu, G., R. Vollrath, and R. W. Davis. 1986. Separation of large DNA molecules by contour-clamped homogeneous electric fields. Science 234: 1582-1585.

10. Doebbeling, B. N., P. F. Lehmann, R. J. Hollis, L. Wu, A. F. Widmer, A. Voss, and M. A. Pfaller. 1991. Comparison of pulsed-field gel electrophoresis with isoenzyme profiles as a typing system for Candida tropicalis. Clin. Infect. Dis 16:377-383.

11. Doi, M., M. Homma, A. Chindamporn, and K. Tanaka. 1992. Estimation of chromosome number and size by pulsed-field gel electrophoresis (PFGE) in medically important Candida species. J. Gen. Microbiol. 138:2243-2251.

12. Feo, M. 1977. The "nascent culture" and its use. Mycopathologia 63:185186.

13. Fox, R., K. R. Neal, C. L. S. Leen, M. E. Ellis, and B. K. Mandal. 1991 Fluconazole-resistant Candida in AIDS. J. Infect. 22:201-203.

14. Galgiani, J. N. 1990. Susceptibility of Candida albicans and other yeasts to fluconazole: relation between in vitro and in vivo studies. Rev. Infect. Dis. 12S:272-275.

15. Goldman, M. J., J. C. Pottage, and D. C. Weaver. 1993. Candida krusel fungemia-report of four cases and review of the literature. Medicine 3:143150.

16. Iwaguchi, S.-H., M. Homma, and K. Tanaka. 1990. Variation in the electrophoretic karyotype analysed by the assignment of DNA probes in Candido albicans. J. Gen. Microbiol, 136:2433-2442.

17. Khattak, N. M., J. P. Burnie, R. C. Matthews, and B. A. Oppenheim. 1992 Clamped homogeneous electric field gel electrophoresis typing of Torulopsis glabrata isolates causing nosocomial infections. J. Clin. Microbiol. 30:22112215 .

18. Magee, B. B., Y. Koltin, J. A. Gorman, and P. T. Magee. 1988. Assignment of clonal genes to the seven electrophoretically separated $C$. albicans chromosomes. Mol. Cell. Biol. 8:4722-4726.

19. Mahrous, M., T. J. Lott, S. A. Meyer, A. D. Sawant, and D. G. Ahearn. 1991. Electrophoretic karyotyping of typical and atypical Candida albicans. J. Clin.
Microbiol. 28:876-881.

20. Merz, W. G., C. Connelly, and P. Hieter. 1988. Variation of electrophoretic karyotypes among clinical isolates of Candida albicans. J. Clin. Microbiol. 26:842-845.

21. Merz, W. G., J. E. Karp, D. Schron, and R. Saral. 1986. Increased incidence of fungemia caused by Candida knusei. J. Clin. Microbiol. 24:581-584.

22. Meyer, S. A., D. G. Ahearn, and D. Yarrow. 1984. Candida inconspicua (Lodder et Kreger-Van Rij), p. 708-709. In N. J. W. Kreger-van Rij (ed.), The yeasts: a taxonomic study, 3rd ed. North-Holland, Amsterdam.

23. Milne, L. J. R. 1989. Fungi, p. 680-699. In Mackie and MacCartney's practical medical microbiology, 13th ed. Churchill Livingstone, Edinburgh.

24. Monod, M., S. Porchet, F. Baudraz-Rosselet, and E. Frenk. 1990. The identification of pathogenic yeast strains by electrophoretic analysis of their chromosomes. J. Med. Microbiol. 32:123-129.

25. Persons, D. A., M. Laughlin, D. Tanner, J. Perfect, J. P. Gockerman, and J. W. Hathorn. 1991. Fluconazole and Candida krusei fungemia. N. Engl. J. Med. 325:1315.

26. Pittet, D., M. Monod, I. Filthuth, E. Frenk, P. M. Suter, and R. Auckenthaler. 1991. Contour-clamped homogeneous electric field gel electrophoresis as a powerful epidemiological tool in yeast infections. Am. J. Med. 91:25652635 .

27. Schwartz, D. C., and C. R. Cantor. 1984. Separation of yeast chromosomesized DNAs by pulsed field gradient gel electrophoresis. Cell 37:65-67.

28. Van Uden, N., and H. Buckley. 1970. Candida knusei (Cast.) Berkhout, p. 982-986. In J. Lodder (ed.), The yeasts: a taxonomic study, 2nd ed. North Holland Publishing Co., Amsterdam.

29. Van Uden, N., and H. Buckley. 1970. Candida rugosa (Anderson) Didaens and Lodder, p. 1032-1034. In J. Lodder (ed.), The yeasts: a taxonomic study, 2nd ed. North Holland Publishing Co., Amsterdam.

30. Vasquez, J. A., A. Beckeley, J. D. Sobel, and M. J. Zervos. 1993. Comparison of restriction enzyme analysis versus pulsed-field gradient gel electrophoresis as a typing system for Torulopsis glabrata and Candida species other than $C$. albicans. J. Clin. Microbiol. 31:2021-2030.

31. Wickes, B. L., J. B. Hicks, W. G. Merz, and K. J. Kwon-Chung. 1992. The molecular analysis of synonymy among medically important yeasts within the genus Candida. J. Gen. Microbiol. 138:901-907.

32. Wingard, J. R., W. G. Merz, M. Rinaldi, T. R. Johnson, J. E. Karp, and R. Sarai. 1991. Increase in Candida krusei infection among patients with bone marrow transplantation and neutropenia treated prophylactically with fluconazole. N. Engl. J. Med. 325:1274-1277. 